\title{
A brief analysis of the development of green building technology in Shanxi-take residential buildings as an example
}

\author{
Meng Jinlan ${ }^{1}$, Gao Yubo ${ }^{2, *}$ \\ College of Architect and Civil Engineering, Taiyuan University of Technology, Taiyuan 030024, China
}

\begin{abstract}
Facing the two problems of environmental pollution and resource shortage, human realizes the harm brought by the economic deformity development to nature, and green building arises at the historic moment. In order to promote the application of green building technology in the market, this paper first understand the state of development of green building in domestic, and then combine the environmental factors and energy consumption analysis in Shanxi area, take residential buildings as the object, and analyze the development and application of green building technology briefly in Shanxi area.
\end{abstract}

\section{Introduction}

Facing the severe situation of resources and environment, the construction industry has an unshirkable responsibility. The growth of the construction industry is extremely rapid, the management is relatively extensive, and the density is concentrated and the energy consumption is huge, which brings great pressure to the consumption of domestic resources and the living environment. In order to break the existing situation, the popularization and application of green building technology is imperative.

Concerned about the global architecture, green building will become the theme of the development of the construction industry in the future. Chinese architecture will follow the trend of low carbon and embark on the road of sustainable development. Shanxi province is a large traditional heavy industry province in China. The consumption pattern of resources is extensive and the problem of building energy consumption is prominent. Taiyuan as the capital of Shanxi province, in response to the national call in recent years, made a positive attempt to carry out a large number of green building pilot works, and advocate new construction projects to adopt green building technology.

This article first briefly introduces the development status of green building in China, and then introduces the climate and environmental factors in Shanxi, at last introduces green building technology, respectively, summarizes the green building technology that can be popularized in the region, and as a reference for the development of green building in Shanxi Province in the future.

\section{The development status of green building in China}

The "green building evaluation standard" of GB/T50378 - 2006, formulated by the Ministry of State Construction and the State Quality Inspection Administration in China in 2006, is the first national standard to introduce the relevant content of green building in China. This document has milestone significance in the history of Chinese architecture development. The new version of GB/T50378-2014 "green building evaluation standard" was released in 2014, which promoted the continuous improvement of the green building technology framework, including expanding the scope of the evaluation, making clear the stage of the evaluation, the scientific evaluation method, so that the whole green building is more innovative and the development has the rules. In the field of technology research and development, on the basis of independent innovation, our country continues to introduce advanced foreign technology, such as the green building technology which has been widely used now: CFD environment optimization design, VRV high efficiency HVAC equipment, water permeable ground design and so on.

However, the development of green building in China is still in its infancy. The distribution of green buildings in various provinces and cities in China is quite unbalanced. The application of green building technology is concentrated in the more developed coastal cities, and the overall development degree is also far from the other countries. It is manifested in the following aspects: the green building implementation system is not mature, the technical level is deficient, the design ability is insufficient and the green building economic chain is incomplete.

In recent years, the country has paid more attention to the development of green building industry. On the one hand, green buildings are introduced into the central and western regions through macroscopic regulation and control to achieve the overall development of green buildings. On the other hand, the application and

\footnotetext{
* Corresponding author: Gaoyubo@tyut.edu.cn
} 
promotion of the guarantee housing as the carrier of the national green building technology, and the establishment of a demonstration project of green building technology in various provinces and cities. In addition, the use of renewable energy to promote the restructuring of the building structure, the wide spread of green buildings in the country to promote the development of new industries, to create a win-win layout of the construction industry to reduce the cost of the construction industry and protect the environment and saving resources. At present, on the basis of the development level of green building, our country has clearly defined the development goal of green building. By 2020, the proportion of renewable energy in energy consumption was raised to $30 \%$, green building technology was applied and popularized in a wider range, and the role of green construction in energy conservation and environmental protection was fully played, and the sustainable development of the construction industry was greatly promoted.

\section{Study on climatic and environmental factors in Shanxi area}

\subsection{Environmental factors and green building}

The application of green building technology must give priority to regional factors. In the design, the green building technology should be adapted to the environment, and the balance of the surrounding environment should be maintained throughout the whole life cycle of the building. Therefore, the building in the location, orientation, the performance of the window and the design of the shape of the building must try to resolve the influence of the environmental factors on the energy consumption of the building. At the same time, we should make use of the favorable conditions to improve the performance of the building, and give consideration to the two aspects of the design and technology, and fundamentally reduce the construction energy consumption to achieve sustainable development.

\subsection{Climatic characteristics of Shanxi area}

Shanxi is an inland province in the middle reaches of the Yellow River, belonging to the temperate continental monsoon climate type. Under the influence of monsoon circulation, solar floating and geography and other factors, the characteristics of the four seasons are distinct, the rain and heat are synchronized, the light is sufficient, the frost free period is long, the north and south climate difference is large, the winter and summer temperature change largely and the temperature difference between day and night is big and so on.

\subsection{Energy consumption analysis of residential buildings in Shanxi}

In summer, the power consumption of air conditioner is the key of building energy consumption. The main factors affecting the summer energy consumption of residential buildings in Shanxi are: room orientation and heat storage capacity, the area ratio of window to wall, thermal resistance and heat storage performance of enclosure structure, shadow from the commercial tenant and air infiltration.

In winter, improving the thermal performance and heating mode of the building is the main direction to reduce energy consumption in winter. The residential buildings in Shanxi mainly use the urban heating system heating (central heating). The heat of $40 \%$ of the existing heating system is wasted. This traditional heating mode is mainly heated in the form of air circulation, and the efficiency is low and the energy consumption is large. The main influencing factors are enclosure structure performance, thermal bridge effect of doors and windows, wall thermal insulation performance and so on.

Taking Taiyuan as an example, by the end of 2014, there were 4 million 298 thousand and 9 hundred of permanent residents in Taiyuan, including 3 million 621 thousand and 8 hundred of urban population and 677 thousand and one hundred of rural population. In the same year, the per capita housing area of urban residents was 29.3 square meters, and the per capita housing area in rural areas was about 32.9 square meters. Among them, the housing area which can meet the requirements of national heating building energy saving is only $15 \%$, the thermal performance of residential buildings is generally low, the current energy consumption is not optimistic, and it has great potential for transformation.

\section{Development of green building technology in Shanxi area}

With the rapid development of the times, science and technology, the form and structure of buildings are becoming more and more complex; the green building technology needs to be constantly refined to meet the demand. China is in the peak period of the development of construction industry, which is also the best period to develop green building technology. Residential building is a kind of high building energy consumption in urban buildings. The use of green building technology is very important to reduce the energy consumption of residential buildings. With the acceleration of urbanization in China, we must pay enough attention to the application of green buildings in new residential buildings and existing residential buildings.

\subsection{Green building technology is classified according to energy saving method}

By changing the building itself to reduce energy consumption, this technology is called passive green building technology; and by developing mechanical energy consumption equipment to help reduce building energy consumption, this kind of technology is called active green building technology. It is the essential difference between these two ways whether or not to use external energy dissipation equipment to achieve energy conservation. These two ways also have specific 
implementation methods in residential buildings in Shanxi.

\subsubsection{Passive green building technology}

When carrying out green projects, the first thing to consider is to combine the geographical environment factors and take the lead in using passive building technology to achieve the requirement of reducing energy consumption. Building energy consumption in Shanxi is generally high, which is also the most effective way.

(1) Insulation technology of building exterior wall

Commonly used domestic wall insulation methods are of three kinds: external wall interior thermal insulation, external wall exterior thermal insulation and external wall self thermal insulation. These three technologies have their own advantages and characteristics. After the market verification, relatively mature construction procedure and inspection systems have been formed. At present, Shanxi area started late in this area, with the requirements of policy and reality, Shanxi area has carried out thermal insulation renovation project to residential buildings. In the reconstruction project, the external wall interior thermal insulation technology is mainly used, and a small part of the existing buildings and half of the new buildings are used for the external wall exterior thermal insulation technology.
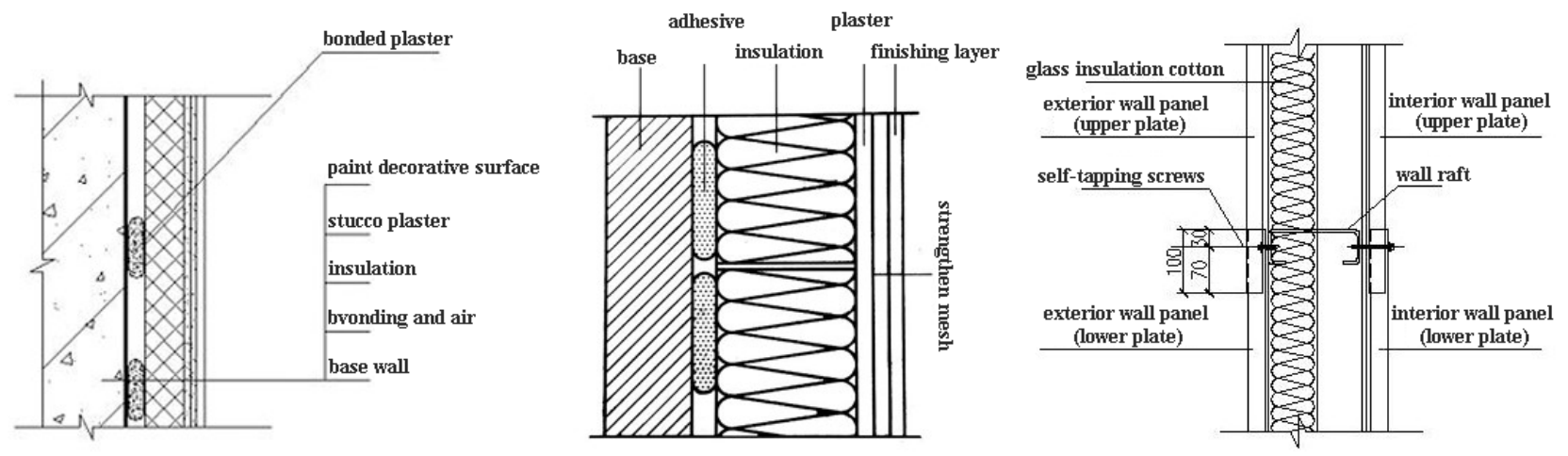

Fig.1. External wall interior thermal insulation, external wall exterior thermal insulation, external wall core thermal insulation

(2) Energy saving technology for building windows

The widely used technologies in our country are bridge cutoff aluminum window frame, Low-E low radiation glass and outer window shading system. The above three technologies can provide various energysaving schemes for the building windows in different areas. The bridge cutoff aluminum window frame mainly solves the heat bridge effect of the window frame and reduces the heat transfer in the room and outside. LOWE low radiation glass is used to solve the influence of solar heat radiation on indoor temperature by coating technology; and the external sun shading system is more convenient for the artificial control of the building to accept the amount of sunlight. In the past few decades, Shanxi province has made two windows transformation. Since 1995, the traditional wooden window frame is changed to aluminum alloy window frame. The second transformation is to upgrade the aluminum alloy window frame to the plastic steel window frame in 2005, and substitute the single layer glass with double insulating glass. However, at present, there are still $65 \%$ of Shanxi's external windows that are unable to meet the requirements of energy saving, and the use of new windows has become a necessary way.

(3) Roof and wall greening technology

In residential buildings, in view of the security problem, dwellers seldom go to roofs in their daily lives, although the concept of green roof has been put forward for many years, the development in the Shanxi area is very limited. On the basis of considering the loading, waterproofing and irrigation methods, It is effective to open up the space and the space of the roof of the city and it is also an important way to reduce the building energy consumption effectively.

(4) Natural ventilation technology of building

There are two main aspects of passive building ventilation technology: first, by changing the orientation of the building, the size and position of the opening, the selection of the air guide system, the form and structure of the building and the arrangement of the building group, to reduce the temperature of the environment, reduce the load of the air conditioning system to reduce the energy consumption; and the second is with the help of heat exchange component to pre cool or pre heat the air entering the building, while auxiliary temperature control equipment is used to control room temperature. Taking Taiyuan city in Shanxi area as an example, Taiyuan is in the "Jinzhong basin", north-west wind perennial and minimum wind speed in summer. Therefore, the construction of Taiyuan has a natural ventilation in summer, and it is suitable to adopt the orientation of facing south with the back to the north, the north facing window is large and south is small, and the draught of residential structure is realized by wind pressure.

\subsubsection{Active green building technology}

(1) Water resources recycling technology

Shanxi province is one of the most scarce water resources provinces in China. We try to solve the problem of water resources shortage in urban development from the three aspects of the recycling of 
water, the use of recycled water and the collection of rainwater, and try to apply the new technology to the building.

(2) Solar energy utilization technology

The development and utilization of solar energy is no stranger to us, and we know that there is still great space for development. In addition to solar water heaters, the rapid development of solar energy utilization technology such as photovoltaic power generation technology in recent years, this technology can realize the direct conversion of natural energy and consumption energy, and will solve the pressure of urban power system to a great extent. In addition, the use of mechanical equipment to fulfill the direct use of sunlight as building lighting system is also actively developing. With the advent of the age of intelligence, the combination of intelligent light guiding system and artificial lighting will lead to the development trend of indoor light environment.

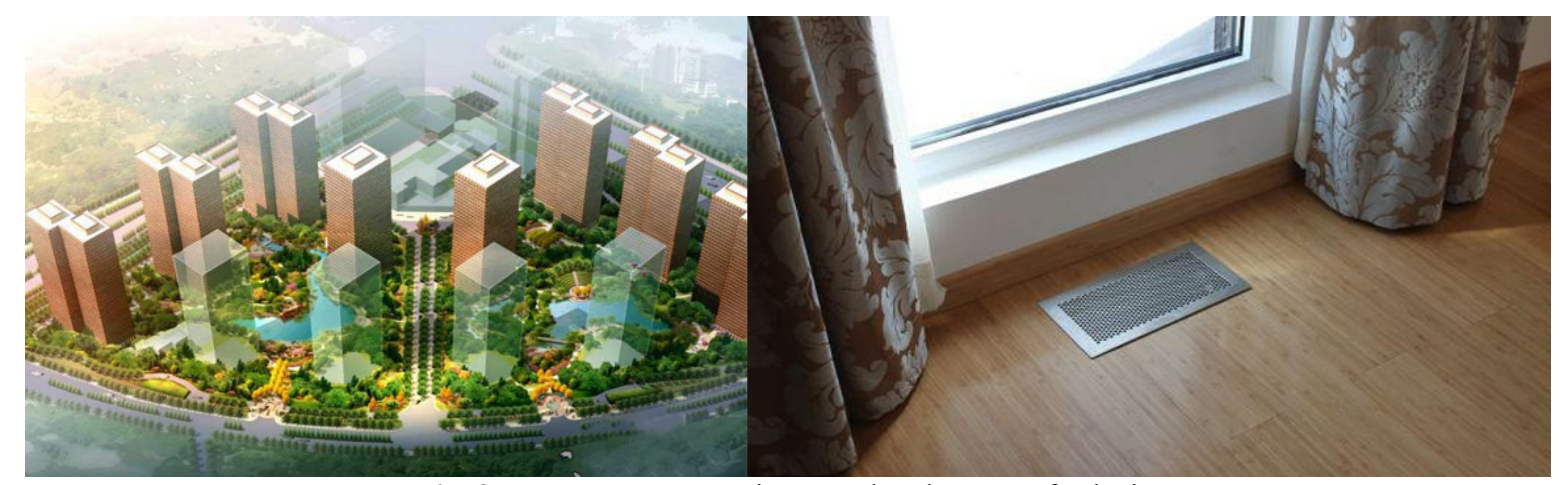

Fig. 2. Wanguo MOMA Taiyuan and replacement fresh air system

\subsection{Classification of green building technology according to application direction}

At present, green building technology is mainly divided into green building technology suitable for public buildings and green building technology suitable for residential buildings according to the building types. The two buildings are quite different in structure and function, so the difference of green building technology applied is quite large.

The goal of residential building design is to meet people's daily life needs, so the form of residential buildings is basically the same. At present, residential buildings in China are dominated by high-rise panels, and the indoor space is relatively independent, and the energy consumption of each household is unbalanced. It needs to choose targeted energy saving technology for suitable residential buildings, and start with energy management and control, and the save energy saving work refined to every household. At present, the green residential building technology with preferable development in China includes metered heating technology, replacement fresh air technology and ceiling thermal radiation technology.

The Wanguo MOMA residential project of Taiyuan is located in the Changfeng Business District of Changfeng West Street in Taiyuan. After calculation, it can be realized of reducing the energy consumption by $35 \%$ on the basis of the national building energy saving target of $60 \%$. Under the condition of no air conditioner and heating system, the indoor environment of constant temperature and constant humidity is achieved by using the replacement fresh air technology and the ceiling thermal radiation technology, which has reached the internationally recognized standard of human suitable environment. The displacement fresh air system is that through the outdoor air heating, humidification, filtering, and so on, after a series of treatment, from the lower position of indoor to the room, takes away the body heat, while generating the lift eliminate the old air. The air supply outlet of the air supply system is located on the floor of the room, not only to fresh air, but also to recycle the heat from the exhaust gas in the room and used for the second time, and no cross pollution is produced. This efficient technology is worth popularizing.

In addition to indoor air, MOMA residential houses use ceiling radiant technology to adjust room temperature. The ceiling radiant system can heat and refrigerate by means of thermal radiation. Unlike the radiant floor heating system, the system adopts the warm water circulation system built by the building; the radiation system of the ceiling is buried in the circulating water pipe in the building concrete floor. In summer, it enters the cold water about 20 oC. In winter, the water temperature is adjusted to about $28 \mathrm{oC}$, and the indoor space is radiated by the way of low temperature circulating water. This system can not only improves energy utilization, but also maintains room temperature in a constant range. It is a new way to solve the problem of residential building heating and cooling. 

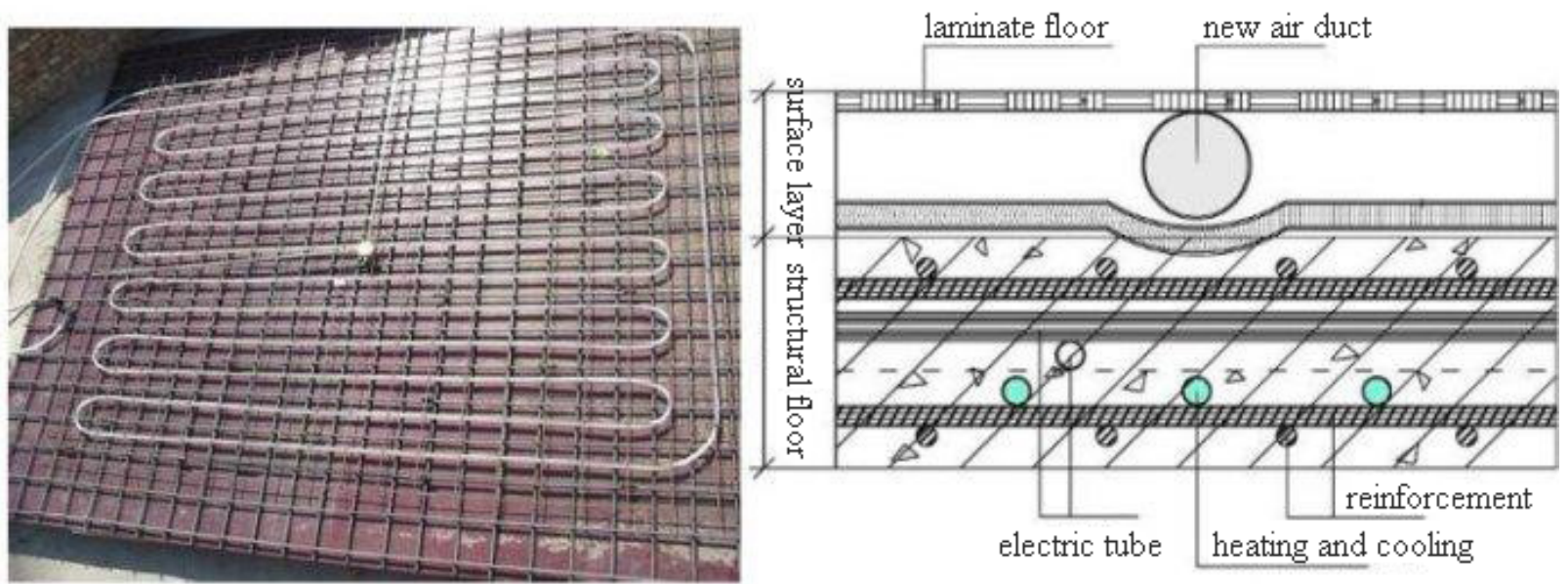

Fig. 3. Application of ceiling radiation system in Wanguo MOMA, Taiyuan

\section{Research prospect}

Green building is a kind of building technology that can really bring environmental dividends to the country and region. As a designer, we need to carry out the work on taking into account the regional characteristics of the region and the features of the building function in the design, and have a deep understanding of the green building technology and the high efficient use of this technology in the design. Combining theory with practice, this paper analyzes the application of green building technology in residential buildings in Shanxi, and provides reference for the development of green building industry of Shanxi province. In order to expect that green building technology can be more widely used in Shanxi area, the construction industry of Shanxi province can gradually close to the strategic goal of sustainable development and conform to the environment friendly times development.

\section{References}

1. Yue L., Niu X., J. Hunan College Fin. \& Eco., (2010)

2. Zhang T., Chinese and foreign entrepreneurs (2015).

3. Wang J., Silicon Valley (2014)

4. Wang F., Shanxi Univ. Fin. \& Eco.,(2013)

5. Dai C. Taiyuan Univ. Tech.,(2010)

6. Yang X., Liu C., Tang L., Sci. \& technology Shangpin, (2015)

7. Xu M.,.Tianjin Univ.,(2016)

8. Cui X., Taiyuan Univ. Tech., (2009).

9. Wu Z., Xi'an Univ. Arch. \& Tech., (2005)

10. Tan J.,. Hebei Univ. Tech.,(2006)

11. Wang L., Tianjin Univ.,(2008)

12. Cui X. Taiyuan Univ. Tech., (2009).

13. Xu B., Jilin Univ.,(2006)

14. Wang A., Taiyuan Univ. Tech., (2016) 